\title{
PEER RELATED FACTORS AFFECTING THE PROVISION OF \\ PSYCHOSOCIAL SUPPORT TO VULNERABLE LEARNERS: A \\ CASE OF SELECTED SECONDARY SCHOOLS IN AMATHOLE \\ DISTRICT IN SOUTH AFRICA
}

\author{
Nyarayi CHINYAMA (iD) $1 *$ \\ Octavia SIBANDA (iD ${ }^{2}$ \\ Shingirayi CHAMISA (iD ${ }^{3}$ \\ Happy Mathew TIRIVANGASI \\ 1 University of Fort Hare, Institute of Social and Economic Research, nchinyama@ufh.ac.za *Correspondent Author. \\ 2 University of Fort Hare, Institute of Social and Economic Research, osibanda@ufh.ac.za \\ 3 University of Free State, Industrial Psychology Department, chamisasf@ufs.ac.za \\ 4 University of Limpopo, Department of Research Administration and Development, happy.tirivangasi@ul.ac.za
}

\section{Article history:}

Submission 30 July 2021

Revision 10 September 2021

Accepted 25 October 2021

Available online 31 December 2021

\section{Keywords:}

Learners,

Peers,

Peer Led Groups,

Peer Counselling,

Psychosocial Support,

Schools.

DOI:

\begin{abstract}
A b s t r a c t
School-based peer groups have been identified as a popular and effective method of providing health education and psychosocial support in schools. Children in developing countries as well as some of the poorest children in developing countries like South Africa face daily risks related to poverty, street crime and violence, poor health, lack or low-quality housing, inadequate and ineffective schools. These children and their families live in crisis which render them vulnerable. Thus, this study noted that there is an increase in social and emotional challenges and several risk factors for vulnerable learners globally and South Africa is not an exception. The incidence of child vulnerability and psychosocial support services have not been studied thoroughly in South Africa yet it is recognized widely that there is an increase in child stress and depression. Much of the psychosocial support services are provided by children themselves in terms of peer education groups. However, much of the research that is currently available on children relies on the reports of teachers and parents. This study learnt from literature that adults consistently underreport the effectiveness of these peer led groups in schools. Following this, the study took a qualitative approach using multiple case studies of 4 secondary schools with children as part of the participants. Pre-coded research instruments were administered to 4 teacher coordinators, 4 peer leaders, 1 district official and 1 learner support agent supervisor. Documents were also analyzed in the form of minutes of the meetings held, learner support agents report and registers. The study found that shortage of resources such as, counselling rooms, transport, attitudes of teachers and parents towards peer led programs, lack of training and cooperation of parents still hampered the progress of peer led programs. The study therefore concluded that there were still a lot of challenges faced by vulnerable children in schools because they were not accessed by their peers due to lack of resources, training, shortage of time and negative attitudes from adults towards children's lives attitudes from adults towards children's lives. The study recommends that peer led groups be part of the large school curriculum with a specific budget to sustain the needs of the peer led groups. The study indicated that there were no networking opportunities amongst peer-led groups due to lack of time, yet this is very important to all successful organizations of a peer group nature. The participants also revealed that peers are better placed if they had counselling rooms, time tabled services, positive attitudes from parents and long-term training on peer counselling.
\end{abstract}




\section{Introduction}

Globally, schools operate in settings characterized by acute forms of social disruptions: disasters, illness, the HIV and AIDS pandemic, poverty, and social injustice (abuse, class interruptions, bullying, rape and COVID-19), which all impact on the psychosocial well-being of children (Knight, HaboushDeloye, Goldberg \& Grob, 2019). These social disruptions lead to serious and long-lasting stressors which render (them) children vulnerable. In South Africa, vulnerable situations of some learners are made worse by the unreliable child-care practices from the community, parents, teachers, and peers (Mwoma \& Pillay, 2015). Children going through social and emotional problems are likely to display a variety of emotions which can affect their schooling or life in general (Ecclestone \& Hayes, 2019). For instance, they can suffer from anxiety, anger, feelings of helplessness and hopelessness, guilt, shame, sleeping disorders and depression, hence; the need for psychosocial support (Weare, 2015). These social disruptions are on the increase globally and have detrimental effects on intelligent quotients (IQ), school achievement, and socio-emotional functioning, hence, their classification as factors causing vulnerability (Kennedy, Flach, Detullio, Millen, Engleber \& Edmonds, 2019). This suggests that there is a need to attend to individuals who are functioning poorly even in the absence of clinical disorders. Thus, schools have several groups offering psychosocial support to vulnerable learners which include social workers, psychologists, teachers, and learners in the form of peer education groups (Birkett \& Espelage, 2015).

Peer education is known as sharing of information and experiences among individuals with something in common (D'Costa, Lobo \& Ward,2021). It aims to assist young people in developing knowledge, attitudes, and skills that are necessary for positive behavior modification through the establishment of accessible and inexpensive preventive and psychosocial support (Al-Khayat,2021). In addition, peer education programs mainly focus on harm reduction information, prevention, and early intervention (Kimmel, Gaeta, Hadland, Hallett, Marshall, 2021). The youth have accepted peer education as a preferred strategy to reach unreachable populations such as high school learners and to approach and discuss topics that are insufficiently addressed or considered taboo within other contexts (Alfeir, 2021). High school learners are at the adolescence stage. Adolescence is an important stage of human life span; which crucial developmental processes occur. Since peers play a critical role in the psychosocial development of most adolescents, peer education is currently considered as a health promotion strategy in adolescents (Chen, Schneider \& Patten,2021).

Peer education is defined as a system of delivering knowledge that improves social learning and provides psychosocial support. This study refers to these groups as peer led groups. Peer led groups take many forms of supportive actions such as love and affirmation and ensure that a child's basic rights are realized through sensitively listening and responding to their peers (Bradshaw, 2016). Such programs assist the vulnerable learners to adjust and cope with challenges they might be facing. The effectiveness of these peer led groups is influenced by many factors such as resources, training of peer leaders and the support from all the stakeholders working with peer led groups. Improving the effectiveness of the peer led programs is therefore crucial since peer education is an effective tool for promoting healthy behaviors among adolescents in schools. The development of this social process depends on the settings, context, and the values and expectations of the participants (Audley \& Jović, 2020). Therefore, designing such programs requires proper preparation, resources, training, supervision, and evaluation of the peer led programs.

Although substantial gains have been made in understanding the ways that young people are both emotionally and physically vulnerable, children still represent an understudied and underserved group. In order to fully understand the nature and scope of children's vulnerability when exposed to disasters, there is need to learn more about experiences that the children have gone through and not from teachers and parents alone. Thus, this study noted that there is value in learning as much as possible, about children's experiences from the adults in their lives, this is despite the fact that research has shown that adults consistently underreport levels of distress and emotional problems in children (Babugura \& McFarlan, 1987). Moreover, this study hopes to develop a participatory child centered research method and approach that offers children and youth the opportunity to give voice to their own thoughts and interpretations of events. Researchers and practitioners will be in a better position to comprehend the full scope of children's needs and vulnerabilities both as victims or as cheer leaders. The argument for examining the effectiveness of peer education programs within the context of constructivism is appropriate in assisting addressing these barriers. This study therefore aims to investigate the peer related factors affecting the provision of psychosocial support to vulnerable learners in Amathole West Education District. 


\section{Literature Review}

\subsection{Resource}

Globally, Nice, Joseph, Kolbert, Hilts, Crothers \& Kratsa (2021) argue that assessment of learner counselling needs is hindered by lack of resources such as psychometrically sound instruments of learners' psychosocial needs. Maturure (2004) found out that in America, effective school peer support services had computer assisted psychosocial support programs, psychosocial support exploration materials, self-development resources, college catalogues and test taking skills packages and booklets. These were put in place to help learners to address developmental needs such as adjusting to their physical changes, handling peer pressure and preventing substance abuse, newsletters, brochures and pamphlets. however, despite these positive initiatives, Deshields, Wells-Di Gregorio, Flowers, Irwin, Nipp, Padgett \& Zebrack (2021) argue that effective American psychosocial support services are hindered by lack of referral resources hence peer support groups in schools with successful comprehensive services recruit volunteers to work in peer led groups as peer educators.

Moreso, Benedek, Gemayel, Senhadji \& Tieman (2021) state that in Finland and Botswana peer support groups are negatively affected by inadequate space and materials that enable peer support groups and their support staff to provide efficient and effective services to vulnerable learners. Tharp, (2018) further indicated that these materials should be allocated in such a way that everyone in the school has equal access. Sima (2018) in a study on Challenges in the provision of Counselling Services in Secondary Schools in Tanzania uncovered that counsellors were mainly challenged by the unavailability of counselling resources, including confidential rooms for conducting interviews. They recommend that the ministry of Education provides peer counselling services in schools more strategically as well as supply them with the required resources. Further to this, research shows that most schools in Tanzania, particularly those in rural areas, are at a disadvantage because they have not been furnished with adequate physical, fiscal and human resources (Haki, 2004 in Sima, 2018).

Thus, the counselling programs should be strong so that they will be able to delineate issues, strategize and establish intervention programs that may assist in closing the achievement gap between these learners and their more advantaged peers. Sima (2018) further highlights that school counselors have been left out of the education reform movements that have been implemented with very little having been done to prepare them for advocacy roles in relation to learners. In Botswana, the meagre resources that are available exist mainly in schools in big cities and towns while the rural schools, especially those with learners from low-income families are ignored (Divanoglo, Trok, Jörgensen, Hultling, Sekakela \& Tasiemski, 2019).

In South Africa, peer led groups are affected by severe economic constraints which have led to the marginalization of the peer support services and the demoralization of its practitioners. One of the major factors that has promoted marginalization is pressure on schools' budgets and these have negatively affected peer psychosocial support services (Ntuli, Mokgatle \& Madiba, 2020). This has been worsened by the country's apartheid legacy of racial oppression and discrimination perpetuated by a wide range of political, socio-economic, and educational inequalities which continue to affect subsequent generations of black people, including learners in need of Learner Counselling Services (Naidoo \& Cartwright, 2020). South African learners are a racially and ethnically diverse community, classified into the racial categories of "African," "Colored," "Indian," and "White." The concept of "Black South African" encompasses "Africans," "Colored," and "Indian"'(Tewolde, 2021:54).

In addition, a smaller segment of the learner population consists of foreign or international from neighboring African countries as well as abroad. The extant literature shows that, South African learners, in general, have been noted to have a range of academic, mental health and psycho-social issues that include mood and anxiety-related disorders; psychotic disorders, substance abuse, and dependence; issues pertaining to identity, sexual orientation, ethnicity, and discrimination; HIV/Aids, bereavement, relationship, and family challenges; peer pressure; historical and current trauma relating to crime and gender-based violence (Bantjes et al., 2019; 2020; Naidoo, 2016). Additionally, difficulties inherent to historically disadvantaged African schools are socio-economic and psycho-social in nature, ranging from a lack of funds to buy basic services and resources.

\subsection{Time}

Another key factor that has been found to affect the effectiveness of psychosocial support services by peer led groups is time. Globally, peer support coordinators' such as teachers complain of heavy teaching loads and other responsibilities such as administrative and clerical duties in the school which leave very little time for them to meet learners needing psychosocial support services (York-Barr, Sommerness, Duke \& Ghere, 2005). In Malaysia, research by Wright-Berryman, Hudnall, Bledsoe \& Lloyd (2018) revealed that schools had less time for psychosocial support duties as much of the time is spent on studying. As such, Besley (2002) advocates for the employment of full-time school peer support groups in schools to overcome the shortage of time. This has been witnessed in Finnish schools, where most of the peer support groups work as full-time school peer supporters 
(Kurunsaari, Tynjälä \& Piirainen, 2021), hence they have more time for the learners.

Farrington \& Ttofi (2009) indicated that the intensity and duration of a program is directly linked to its effectiveness, and other researcherss (Olweus,Solberg \& Breivik, 2020; Ntinda, Maree, Mpofu \& Seeco,2014) also found a 'dose-response' relationship between the number of components of a program that were implemented in a school and its effect on bullying. Farrington \& Ttofi (2009) further states that the duration (number of days) and intensity (number of hours) of the program for children were significantly related to the reduction of bullying and victimization. What these findings show is that peer led programs need to be intensive and long-lasting to have an impact on this troubling problem. It could be that a considerable time period is needed in order to build up an appropriate school ethos that efficiently uses peer led programs. In a study carried out in Ireland Dooley Jugde (2017), participants revealed the need for more time, such as 5-year program time frames, in order to promote long-lasting intervention programs. Dooley Judge (2017) further highlighted that donor-imposed project time limits constrained the full implementation of the project and the process of behavioral change. Informants in the study emphasized that more preparation time should be allotted for materials development so that peer educators were not sent into the field without the necessary support materials.

In South Africa, school peer support groups complain that counsellor-learner ratios are too high and as such this negatively affects their psychosocial support services (Chireshe, 2006).

Moreso, in South African schools there were no periods allocated for psychosocial support services and these were not optimally utilized because of shortage of time (Dhital, Shibanuma, Miyaguchi, Kiriya \& Jimba, 2019). Peer support coordinators' heavy teaching loads and other responsibilities such as administrative and clerical duties in the school leave little time to them to meet learners in need of psychosocial support services.

\subsection{Training}

Globally, lack of proper training of peer supporters has been found to have a negative effect on peer led psychosocial support groups in schools (Mitchell, Purcell, Forsyth, Barry, Hunter, Simpson \& Moore,2020). In America, lack of training on the part of peer supporters negatively affects psychosocial support program evaluation (Maree, Fletcher \& Pienaar, 2018). Moreso, in Uganda, Zimbabwe, Botswana and South Africa several educational planners and heads of institutions are not trained to assist peer led groups in psychosocial support programs (Mtemeri, 2020).
Farrington \& Ttofi (2009) in their research also discovered the need for resources to train more head office staff who could supervise peer educator activities in the schools. They also discovered that training of technical staff for persons involved in peer education programs is not as simple as ensuring that they know how to teach people about knowledge, attitudes, and practices. Their study also revealed that there is need to work on these issues within staff, failure to which will make the whole educational process distorted. In the same study several informants said that the low educational levels of peer educators necessitated additional training that was often not carried out. Evidence from the above researches reveals that peer educator training needs to be more practical and participatory in nature, and structured curricula and support materials are also crucial in order to curb the abstract nature of training of peer educators. Farrington and Ttofi (2009) further aver that peer leaders are trained in hotels with flip charts but when they go to the community they find a totally different scenario. They are unable to fully put into practice what they have been taught for they don't have the teaching aids for demonstration and materials to distribute.

\subsection{Attitudes}

Globally, stakeholders' attitudes affect the effectiveness of peer led groups. Attitudes are stable opinions regarding a person, object or activity, containing a cognitive element (perception and beliefs) and an emotional element (Wade \& Tarvis, 1993 in Moeti, 2016). In Austria and Spain stakeholders with positive feelings about peer support groups have been noted to give a lot of support to peer programs (Zeiler, Kuso, Nitsch, Simek, Adamcik, Herrero \& Waldherr, 2021). In America, negative attitudes of some school administrators, counsellors and learners affect the effectiveness of the psychosocial support programs (Pincus, Hannor-Walker,Wright \& Justice, 2020). The above situation also prevails in Malawi where peer support group services are often seen as ancillary-support services, placing school counsellors mainly in remedial reactive roles that are not seen as mainstream education (Mwale, \& Muula, 2019). In Nepal, it is culturally taboo to discuss sexual and reproductive health between adults and adolescents and youth (Upadhyay, 2016). This scholar posits that expectation of project staff was to break the 'secrecy' surrounding sexual reproduction health, to enable parents, other significant adults, adolescents and youth to discuss sexual reproduction health more openly.

This in turn would lead to an increased demand for sexual reproduction health services (Shariati, Babazadeh, Mousavi \& Najmabadi,2014). For the most part parents appeared willing for their children to receive this information from peer educators or project staff, but in the endline surveys parents were not 
mentioned as a source of information themselves. This suggests that the majority of parents are still not willing to talk with their children about sexual reproduction health issues. Similarly, Shiferaw, Getahun \& Asres, (2014) state that teachers in Ethiopia still have difficulty in discussing sexual reproduction health issues with their learners but will often allow peer educators to undertake sessions within school time.

Furthermore, Mugai (2020) argues that in Uganda, some parents tend to resist psychosocial support services because of its ambiguity in the expectations of school counsellors and teachers regarding the school counsellor's role. Dickens (2016) adds that school administrators and policy makers in South Africa have raised concerns about the vagueness of the outcomes of peer support services. Moreover, peer support services may not survive without school administrative support for their implementation and maintenance (Fortuna, Naslund, LaCroix, Bianco, Brooks, Zisman-Ilani \& Deegan, 2020). Sahlberg (2021) states that it is unfortunate that many policies makers' world over, including South African public schools are less impressed by psychological development among learners, instead, they are more impressed by improved grades and test scores. Thus, this study sought to find out whether the effectiveness of peer led groups is affected by the attitudes of headmasters, school counsellors, learners and parents.

\section{Research Methodology}

This study adopted an interpretive paradigm with the intention of understanding the experiences of the stakeholders in peer led groups. The interpretive paradigm is based on the concept that "reality is socially constructed" (Pilarska, 2021:56). Hence, the interpretive paradigm was suitable for this study as it allowed the researchers to interact with participants as well as relying upon the participants' views on the factors affecting the effectiveness of peer led groups (Yong, Husin \& Kamarudin, 2021).

\subsection{Research Approach and Research Design}

The study adopted the qualitative approach which allowed the researchers to meet the participants in their natural settings and to probe them seeking to understand the effectiveness of peer led groups in learners experiencing psychological problems (Erath, Pellegrino, DiGennaro Reed, Ruby, Blackman \& Novak, 2021). The researchers employed a multiple case study design of 4 secondary schools in Amathole West District. A multiple case study research design was suitable for this study because it enabled the researchers to get immersed in the participants' actual feelings. The research design was also commensurate because it allowed the researchers to get in-depth and detailed understanding of patterns and trends emerging from the interviews and document analysis on the challenges faced peer led groups in the provision of psychosocial support. This study is focused on one of the larger districts in the Eastern Cape Province of South Africa- Amathole District. This area, Amathole West District was purposively considered as the population frame of the study because of easy access in line with the resources available at the time of the study. A total number of 55 Secondary Schools were identified from which only four schools were further purposively selected for the study based on the availability of peer led groups, convenience, and feasibility.

\subsection{Sample and Sampling Techniques}

The participants were purposively selected, and the sample included a multiple case study of 4 schools in Amathole West District. Pre-coded research instruments were administered to 4 teacher coordinators, 4 peer leaders, 1 district official and 1 learner support agent supervisor. Purposive selection of the schools was justified in this study because the researchers were interested in schools which were accessible and had functional peer led groups that were established and with some experiences.

\subsection{Research Instruments}

The researchers employed three research instruments namely: semi-structured interviews, focus groups, and document analysis. Below is a description of the instruments employed in the study: Semi structured interviews were preferred to other forms of interviews in this study because they offered a platform for conversation with the intention that the researchers explore with the participant her or his views, ideas, beliefs and attitudes concerning peer related factors affecting the provision of psychosocial support to vulnerable learners by peer led groups (Prior, 2016; Nyumba, Wilson, Derrick \& Mukherjee, 2018). The study also used focus group interactions which widened the range of responses and also activated forgotten details of experience that may have discouraged participants from disclosing information. Document analysis was also used as a way of triangulating the data collection instruments.

\subsection{Trustworthiness and Credibility}

Issues of trustworthiness and credibility were obtained through use of multiple data collection instruments (triangulation) in this case interviews with various participants holding different positions in the education sphere as well as the learners who worked with peer led groups themselves. Member checking allowed the researchers to ask the respondents to verify and confirm findings of the study.

\subsection{Data Analysis}

The data collected was coded into common themes as well as writing stories to uncover the main issues arising. The qualitative 
data was organized into categories, general ideas, concepts or similar features. The issues arising from the interviews, focus groups and the document analysis, were put together as findings for the study.

\subsection{Ethical Considerations}

In this study, all ethical considerations were observed by obtaining ethical clearance from the University of Fort Hare. Permission was sought from the Department of Education and schools to obtain information from participants (negotiation of entry). More so, informed consent, voluntary participation, anonymity and confidentiality were also observed.

\section{Findings}

The researchers sought to find out the factors affecting the implementation of peer led psychosocial support programs in schools. Peer group members were asked about their views on the factors affecting the provision of psychosocial support to vulnerable learners in their schools. Findings were solicited from peer leaders, peer group members in focus groups and teacher coordinators. Participants revealed that several factors hindered the implementation of peer led groups in the provision of psychosocial support to vulnerable learners. This included lack of resources, training, negative attitudes and lack of time.

\subsection{Lack of Resources}

Participants indicated that peer related factors affecting provision of psychosocial support in their schools was shortage of resources and this seriously affected the implementation of peer led groups. Resources mentioned by the participants included information on psychosocial support, counselling rooms as well as more manpower. Peer leader 1 had this to say:

We do not have counselling rooms in the school. We usually use the library, but sometimes teachers use the library for meeting, we need closed rooms where we can meet with our learner support agents and the vulnerable learners who seek for our help.

Peer leader 2 also added:

There are no materials to display, for example information on career guidance or health in an area where we can always refer to this information. We have no rooms to work from, so most of the time we discuss in the playground.

In addition, Peer-leader 4 elaborated that:

We use the old buildings behind the school as counselling rooms and sometimes we find the big boys sitting there and they do not want to move. The whole ground is full, so we end up talking while standing, so there is no privacy.

Learner support agents work directly with peer leaders in the schools. The participants generally agreed that the schools where they worked in lacked resources.

Learner support agent 1 also said:

The counselling room is near the administration building. Learners do not want to visit the counselling room they will be shy because that place is in the face of everyone including visitors.

Learner support agent 2 explained:

Some learners have stopped visiting the peer leaders because we sit under the shade of a tree with others listening to them discussing confidential information with them. Sometimes I see the peer leaders, learner support agents and their peers in the library. The library is not functional so they choose to go and work from that side. But sometimes we hold our cluster meetings there and we disturb them.

We do not have a specific budget for peer led groups because it is part of the Health Advisory committee, so this group does not have enough attention from the school although learners are bringing forward a lot of information that these learners could not disclose to their adults, that is teachers and parents.

Teacher 4 had this to say:

We use learner helpers to network with their peers but the challenge is hat of transport as a resource. We need money to do outreach programs but we cannot do that because we are limited financially.

Learner support agent supervisor:

There are no reception areas, private rooms and conference rooms for peer group sessions nor secure storage areas for learner records. The learner support agents in schools do not have working space. Some work from old buildings, some from libraries and some under the shades of trees. This includes the peer leaders. As a result, our clients (vulnerable learners do not feel free to come and consult with us because they are shy to come to us. 
The district official also reiterated:

Our program is greatly affected due to lack of counselling rooms, our numbers are big in the schools, so there are no rooms to spare for these support programs.

The researcherss were able to access files for learner support agents in the school. The files had reports which were written for the district officials. In the reports there were section where the learner support agents were supposed to write their challenges in the carrying out of their duties. All the four Learner support agents highlighted that there was shortage if resources such as counselling rooms. It further emerged from the learner support agents that they all mentioned that the problems were not yet been addressed since some peer led groups operated under trees.

\subsection{Negative Attitudes of those who Support \\ Peer Led Groups}

Peer group members in all the schools indicated that they had challenges in that their elders who were supposed to give them support had negative attitudes towards their peer groups. The school-based support teams in the schools were not functional and peer led groups were operating with the assistance of a learner support agent and learner support agent supervisors. The general feeling from the teachers in the school-based support teams was such that peer led groups were not mature enough to handle some of the social issues that the vulnerable learners experienced.

Peer leader 1 had this to say:

We work with the learner support agent but when she is not there is no one to take the reports because we do not know whom to report to. We cannot tell teachers, yhoo, like Mrs X she comes to class and start talking about it.

Peer leader 2 and 3 had the same sentiments:

Peer leader 2:

Teachers and our parents feel that we should be busy with our school work and leave other children alone. When I told my mother that I am a peer leader she thought of a prefect and I explained that I am not a prefect but I am supporting other learners by identifying their needs and bringing them to the attention of the learner support agent.

Our peers do not believe in us. They just think that since we are also learners and children like them we do not have anything of assistance to give to them. In my school I have been victimized because my colleagues think I am a spy for the teachers, because I always report what I see even in the playground to the teachers.
Teacher 1 said:

Negative attitudes of some school administrators are shown in my school when the Learner support agent is sometimes given a class to teach other subjects and not anything related to their jobs. They teach EMS here. It was better if it was Life Orientation. So psychosocial support is taken very lightly by some school administrators.

The public, like parents are openly critical and are beginning to question the value of peer support groups because they do not believe that learners have any impact in psychosocial support for their peers. They are also complaining about their children being spied on by other children.

Teacher 3 reiterated:

In my school this program is not functioning well because the principal sees the program as not essential and gives the service lower priority. She always says we should concentrate on the core business. Some teachers who are not LO teachers do not want to assist in peer led groups although they are in the school-based support team. They always question the role of peer led groups saying that they are not capable of counselling other learners.

When the researcherss asked the learner support agents to comment they all agreed that communities had mixed feelings with the existence of peer led groups in schools. Learner support agent 1 commented:

My principal has a negative attitude towards this program, and she does not believe that the peer leaders that we have chosen to assist us can assist their peers. As a result, we do not have any publicity in the school. We want to hold concerts in the community hall but she says the school does not have money to buy food for the learners when they go there.

Learner support agent supervisor:

A general feeling is that they learner support agents are not fulltime personnel, and they are relying on a stipend so some of them are busy looking for piece jobs to supplement this job. It needs someone with a positive attitude to work for a small stipend like this.

DO: There are not committed members of the HAC in the schools that I am working with. We only have teachers who accompany their learners to the training. So more still needs to be done in order to encourage the stakeholders to be part of the peer led groups. They must change their attitudes. 
In their reports, Learner Support Agents and peer leaders indicated that they struggled to get financial assistance from the school administrators. Some parents were reported to have refused to sign indemnity forms for their children who were supposed to go for training arguing that they did not like it when their children wasted time assisting their peers.

\subsection{Lack of Training of Peer Leaders}

This study sought to find out the nature of training that the peer supporters get and how it affects the effectiveness of the psychosocial support services in the schools. Most of the participants explained how training affects the effectiveness of peer led groups.

Peer leader 1:

We were trained for three days in a hotel. We have never been trained again. We were given cases to study and we were asked how we can help the people in those cases. Some of the cases were not practical for me, like someone coming to me telling me they have been abused by their uncle. This needs parents to check on their children's wellbeing, so the training should include parents too. I am not happy with the three days of training. We need more training time because we hurriedly touch on some of the issues because we will be rushing back home. We were supposed to go back home, so with me it was not good. I needed more time to ask questions because we had a lot on our minds as well that we needed clarity on.

Teacher 1 also said:

Training is done for three days but I think the time should increase. And training I think should involve even other teachers not LO teachers only but all of them including the parents, even when they start with the SGB members so that they know what is required for the school to support vulnerable learners. Moreover, peer leaders need more training in psychosocial support. They are young but they can be trained to identify their vulnerable peer fellows.

Learner support agent supervisor:

I have seen that there were some learners who were not trained to be peer leaders because the training is done once at the beginning of the year. It will be better if training was done throughout the year so that even if some peer leaders transfer, we may replace them with the newcomers.

The district official also shared his experience with the peer led groups and this what she had to say:
I am very much aware that the training needs more time but there is nothing much that we can do as program coordinators at the district level. We do not have the trainers within the education department. We outsource the trainers, so it is very difficult to actually do justice in this regard.

All the participants report highlighted that they needed more time for training. They all indicated in their comment sections of their program evaluation forms that they felt that three days was not enough for training.

\subsection{Lack of Time}

When asked to explain the factors affecting the provision of psychosocial support to vulnerable learners, the participants gave various opinions. Peer leaders perceived school counsellor effectiveness to be related to the availability of time for direct contact of counsellors with learners and accessibility of peer support services to learners, parents and teachers.

Peer leader 1 had this to say:

There is no time to work with our peers because we are also learning. Our time table does not have anything related to what we are doing, so we are not able to do anything officially in terms of peer education. We want our activities to be placed on the time table like all other activities so that we can get time to do our work properly.

Peer leader two also reiterated what peer leader one had said:

There is no time for peer led activities. We need more time to engage with our peers. There is no peer education on the time table.

Teacher 1 had this to say:

There is no time on the part of learners to befriend their peers or conduct the indabas because the peer led group sessions are not time tabled. So it is very difficult for the learners to create time for this. Moreover, we need to be time tabled. We are struggling to make impact in schools because we do not have enough contact time with the vulnerable learners. We just go to class and teach. We need peer activities to be time tabled.

Learner support agents were also asked whether the time that was allocated for peer support was enough. Generally, all learner support agents agreed that the time allocated for peer education was inadequate because the program was not even there on school time tables. 
Learner support agent 1 summed this up:

I think that the schools did not plan for peer led groups, they did not even adjust their time tables to accommodate us as learner support agents, and so we do not have time allocated to us. I go to children's classes when a teacher is absent. Most of the time I am told to teach the learners that particular subject and not even do my work as a learner support agent. It was better if I was teaching them Life orientation. I sometimes ask for time from other teachers just to teach general life orientation topics but I am finding it hard to get time for one on one consultation with the children. When school is out they go home...their transport will be waiting for them.

Learner support agent supervisor:

I am supervising learner support agents in 20 schools as a facilitator of the implementation of the program. I do not have enough time to do all the duties that I am supposed to do. It is therefore difficult to make a follow up if you are sometimes not around the school.

DO also added:

Time is very difficult to come by. As a result, the whole program is full of hiccups. We do not have enough time to do meetings because teachers and children are always busy during the term. It is not easy to create time since the programs are not time tabled. I would advise the department that the program should be part of the school programs so that it can be allocated some time on the time table. Even 30 minutes is enough.

The researcherss checked the time tables in all the schools, there was no time allocated for peer led groups. There was time for Life Orientation and there were teachers' names there who happened to be program coordinators of the peer led groups. They also confirmed that they could not share their time with learner support agents because they had content to teach and the content was assessed. Thus, the above responses revealed that time, attitudes and resources were some of the factors affecting the effectiveness of peer led groups in schools

\section{Discussion of Results}

\subsection{Lack of Resources}

The study revealed that peer led groups needed resources such as counselling rooms. The findings are in line with Chireshe (2009) who concluded that effective peer support services in American schools have adequate resources, equipment and space. All the schools did not meet the standards suggested by Badza, (2005) that schools should have a Counselling Centre with a reception area, private offices, and conference rooms for group sessions as well as, secure storage areas for learner records. Moreso, participants revealed that they did not have psychosocial support. In addition, Mbabazi and Bagaya (2013) suggest that counselling centres should store and display career and college materials in an area where learners can have access. More so, Maturure (2004) found out that in America effective school peer support services had the following materials: computers for computer- assisted psychosocial support programs, psychosocial support exploration materials, self-development resources, college catalogues, test taking skills packages. In addition, booklets that help learners address developmental needs such as adjusting to their physical changes, handling peer pressure and preventing substance abuse, newsletters, brochures and pamphlets were also identified as part of effective school peer support services.

In addition, the findings revealed that consultation rooms in some schools did not exist and those that existed were not located at centres. As a result, this failed to attract vulnerable learners to visit them because such centres were not located in such a way that everyone in the school has equal access as suggested by Tharp (2018). Schmidt (2016) also buttressed that counselling centres were not supposed to be near the administration buildings because the vulnerable learners will associate the counsellor with administration. A study carried by Kapp (2020) in America, where assessment of learner counselling needs is hindered by lack of psychometrically sound instruments of learners' psychosocial needs also aligns with the extant literature and the findings of the study.

Participants revealed that there were high learner ratios, thus Gysbers \& Henderson (2001:252) in Chireshe 2006 suggests that peer support groups with successful comprehensive services recruit volunteers for the school, generate support from business and industries who donate money to pay peer supports team members such as learner support agents and supervisors. The findings of this study align with Chireshe (2006) who found out that in Zimbabwe there were severe economic constraints which led to the marginalization of peer support services thereby demoralizing its practitioners. Thus, Riele (2006) lamented that schools with pressures on schools' budgets have resulted in the marginalization of peer psychosocial support services.

\subsection{Lack of Time}

A key factor that has also been found to affect the provision of psychosocial support in this study is time. The results of the study were in line with Mekgwe \& Kok, (2017)'s findings which established that there are no lessons allocated for psychosocial support services in schools in Botswana. Moreso, peer support coordinators' heavy teaching loads hindered schools to run the 
peer support programs well. This is in line with Mintah (2012) who claimed that responsibilities such as administrative and clerical duties in the school leave little time for them to meet learners needing psychosocial support services. To curb this challenge Besley (2002) in Chireshe (2006) advocates for the employment of full-time school peer support groups in schools who should be paid as full-time practitioners so that they can only focus on their work to overcome the shortage of time that is currently being experienced in a majority of schools. This worked well in Singapore and Zimbabwean schools where most of the peer support groups worked as full-time school peer supporters (Low, 2018; Chidarikire, 2017) hence they had more time for the learners.

\subsection{Lack of Training}

The results of this study also indicated that there was lack of adequate training of peer leaders and this affected the implementation of peer led psychosocial support programs in schools. Peer leaders may be prevented from meeting the needs of learners by increasing the number of cases due to inadequate training of peer leaders (Crooks, Jaffe, Dunlop, Kerry \& ExnerCortens, 2019). The same findings were also found in Uganda where "many educational planners and heads of institutions were not trained in psychosocial support methods" (Rutondoki, 2000: 15) in Kiptala \& Kipruto, (2021). Hence, some of the school leaders did not care about the importance of psychosocial support services in their schools.

\subsection{Negative Attitudes of Adults Supporting Peer Led Groups}

The findings also indicated that negative attitudes from school leaders and parents affect the implementation and effectiveness of psychosocial support programs in schools. The findings of this study were in line with the findings of previous study which revealed that attitudes of some school administrators, counsellors and learners affected the effectiveness of the psychosocial support programs. Thus, in Kenya Ntwiga, (2015) advised that administrators and teachers in schools should allocate resources for anything outside their conventional perceptions-ofclassroom-activities. The findings also revealed that there is generally a lack of appreciation for the contributions peer led groups make in schools. For instance, research shows that administrators and the general public in America are openly critical and are beginning to question the value of peer support groups since "most school counselors do not receive program evaluation training during pre-service experiences", (Trevisan \& Hubert (2001) in Badrujaman, Luawo \& Cahyawulan,2018; Lusky \& Hayes, (2001) in Köse, 2019).
Lastly, this study found out that this study indicated that some parents had negative attitudes towards peer led groups because of different cultural practices and beliefs which do not cater for psychosocial support services. As a result, some parents were reluctant to support their children when doing these services because they are not part of their culture. This is in line with Chireshe (2006) who revealed that parents were more impressed by improved grades and test scores of their children because it is difficult to claim credit for improved performance on tests to school counselling. In Kenya Abuya, Wekulo \& Muhia (2018) suggests that peer led groups should work with parent volunteers to enable them to see all learners seeking their help.

\section{Conclusions}

The study revealed that peer led groups had challenges in implementing peer led programs. These challenges emanated from lack of resources such as time, space as in venues for counselling, adequate training for peer leaders and support for the peer led groups. The study concluded that there were several factors affecting the provision of psychosocial support to vulnerable learners. There were no networking opportunities amongst peer-led groups due to lack of time, yet this is very important to all successful organizations of a peer group nature. The participants also revealed that peers are better placed if they have counselling rooms, time tabled peer services, positive attitudes from parents and training on peer counselling.

More so, the results of the study, the necessity for health professionals to provide emotional support in South African Secondary schools is apparent. The programs pertaining to student wellbeing through psychosocial support require more qualified and experienced specialists. On the other hand, the study revealed that this may be a challenge in settings such as township high schools, where the government and school authorities do not provide adequate support. Furthermore, South Africa has a serious deficit of mental health experts, hence peer led groups in schools could cover this gap. The Health Systems Trust and the Psychological Society of South Africa (PsySSA) reveals that the Department of Health employs 0.32 psychiatrists for every 10,000 persons and 0.7 clinical psychologists.

The results of this study show that a peer leader-mediated intervention alone may not be enough to increase students' wellbeing. The findings, on the other hand, may aid policymakers in recognizing the need for policy adjustments to include health experts in schools. When all stakeholders understand the importance of the wellbeing of students, more resources such as counselling rooms and other materials will be easily accessible or rather will be made readily available by the schools and communities at large. Refresher training for peer leaders, 
students, counselors, teachers, and parents could help keep the momentum going in the direction of preserving students' psychological well-being. More focused and longer training is necessary to enlighten parents that psychological well-being affects the grades and test scores of their children. In addition, the results of the study support the value of assessing and instilling the culture of psychological reliance and prolonged follow-up is essential, particularly with parents and learners.

\section{Recommendations}

This study recommends that schools should have well-trained teachers to assist the peer-led groups with the appropriate decisions to net-work. Schools should also make beneficial home visits which bring in parents as critical members of the counselling processes in the schools. Lastly, psychosocial support should be implemented as a large school program which should be given an independent budget, so that peer led groups may be able to provide adequate resources for learners needing psychosocial support.

The results of the study direct that training psychosocial specialists and placing them in schools around the nation would necessitate significant policy changes, which may require an extended period in a developing country like South Africa. Meanwhile, peer leader-mediated interventions may be a more viable and long-term approach for addressing adolescent psychological issues earlier. However, more targeted, and extensive training may be required for the peer leaders to timely refer those with more serious difficulties to specialists for further assistance. Lastly, the study's findings suggest that in lowresourced schools, training school teachers on psychosocial issues and advocating for student well-being to parents and school administrators may be practical and worthwhile.

\section{References}

1. Abuya, B. A., Wekulo, P., \& Muhia, N. (2018). Support to children's education in the urban slums of Nairobi: Community and parents' perceptions with an expanded phase of an education intervention program. Qualitative Research in Education, 7(2), 118-143. https://doi.org/10.17583/qre.2018.3240

2. Alfieri, C. (2021). Modifying Teachers' Didactic Praxeologies in the Perspective of the Paradigm of Questioning the World: The Case of the Technological-Theoretical Moment. In Extended Abstracts Spring 2019 (pp. 3-11). Birkhäuser, Cham. https://doi.org/10.1007/978-3-030-76413-5_1

3. Al-Khayat, A. M. (2021). Exploring the impact of the displaced Happy Helping Hand app for Syrian adolescents in Lebanon. Digitalized Psychosocial
Support in Education. Master's thesis. Oslo Metropolitan University.

4. Audley, S., \& Jović, S. (2020). Making meaning of children's social interactions: The value tensions among school, classroom, and peer culture. Learning, Culture and Social Interaction, 24, 100357. https://doi.org/10.1016/j.1csi.2019.100357

5. Badrujaman, A., Luawo, M. I. R., \& Cahyawulan, W. (2018). Accountability of Layanan Dasar by school counsellor in junior high school in East Jakarta on school principals' perspective. Konselor, 7(4), 145 150. https://doi.org/10.24036/020187410740-0-00

6. Bantjes, J., \& Mapaling, C. (2021). "I'm Not Afraid of Dying Because I've Got Nothing to Lose": Young Men in South Africa Talk About Nonfatal Suicidal Behavior. American journal of men's health, 15(2). https://doi.org/10.1177/1557988321996154

7. Benedek, D., Gemayel, E. R., Senhadji, A. S., \& Tieman, A. F. (2021). A Post-Pandemic Assessment of the Sustainable Development Goals. Staff Discussion Notes, 2021(003). https://doi.org/10.5089/9781498314909.006

8. Besley, A. C. (2002). Into the 21st Century: The McCrone and McConnell Reports-Opening the Possibility for Introducing Full-Time School Counsellors into Scottish Schools. Scottish Educational Review, 34 (1), 61-75. https://doi.org/10.1007/s10798-004-6194-3

9. Bradshaw, J. (Ed.). (2016). The Well-being of Children in the UK. Policy Press. Available at: https://books.google.co.za/books?hl=en \&lr=\&id=zQ $\underline{\text { VDDwAAQBAJ\&oi }=\text { fnd \&pg }=\text { PR } 1 \& d q=\text { Bradshaw },+}$ J.+(Ed.).+(2016).+The+Well-

being+of+Children+in+the+UK.+Policy+Press\&ots= 7RPExJyk-

O\&sig=ZThBaUJpyQ7zEb4ppHBUFP9XxX8\&redir esc=y\#v=onepage \&q=Bradshaw $\% 2 \mathrm{C} \% 20 \mathrm{~J} . \% 20(\mathrm{Ed}$ .).\%20(2016).\%20The\%20Wellbeing $\% 20$ of $\% 20$ Children $\% 20$ in $\% 20$ the $\% 20$ UK. $\% 20$ Policy \%20Press\&f=false

10. Chen, Y. L., Schneider, M., \& Patten, K. (2021). Exploring interpersonal and environmental factors of autistic adolescents' peer engagement in integrated education.

Autism. https://doi.org/10.1177/13623613211046158

11. Chidarikire, M. (2017). A peer counselling strategy for alleviating drug abuse in Zimbabwean rural learning ecologies (Doctoral dissertation, University of the Free State). (Hardcopy). 
12. Chireshe, R. (2013). Peer counselling in Zimbabwean secondary schools. International Journal of Educational Sciences, 5(4), 349-354. https://doi.org/10.1080/09751122.2013.11890096

13. Crooks, C. V., Jaffe, P., Dunlop, C., Kerry, A., \& Exner-Cortens, D. (2019). Preventing genderbased violence among adolescents and young adults: lessons from 25 years of program development and evaluation. Violence against women, 25(1), 29-55. https://doi.org/10.1177/1077801218815778

14. D’Costa, B., Lobo, R., \& Ward, J. (2021). Lessons learned from the implementation of the Young Deadly Free peer education programme in remote and very remote Australian Aboriginal communities. Sex Education, $1-15$. https://doi.org/10.1080/14681811.2021.1879775

15. Deshields, T. L., Wells-Di Gregorio, S., Flowers, S. R., Irwin, K. E., Nipp, R., Padgett, L., \& Zebrack, B. (2021). Addressing distress management challenges: Recommendations from the consensus panel of the American Psychosocial Oncology Society and the Association of Oncology Social Work. CA: A Cancer Journal for Clinicians. https://doi.org/10.3322/caac.21672

16. Dhital, R., Shibanuma, A., Miyaguchi, M., Kiriya, J., \& Jimba, M. (2019). Effect of psycho-social support by teachers on improving mental health and hope of adolescents in an earthquake-affected district in Nepal: A cluster randomized controlled trial. PloS one,

14(10).

https://doi.org/10.1371/journal.pone.0223046

17. Dickens, L. (2016). The contribution of resilience to the 12-month transitional outcomes of care-leavers in South Africa (Doctoral dissertation, University of Johannesburg). Available at: https://ujcontent.uj.ac.za/vital/access/manager/Reposi tory/uj:20833?site name=GlobalView

18. Dooley Judge, D. (2017). Demand and provision of school counselling in primary schools in Ireland (Doctoral dissertation, Dublin City University). Available at: http://doras.dcu.ie/22010/

19. Ecclestone, K., \& Hayes, D. (2019). The dangerous rise of therapeutic education. London: Routledge. https://doi.org/10.4324/9780429401039

20. Erath, T. G., Pellegrino, A. J., DiGennaro Reed, F. D., Ruby, S. A., Blackman, A. L., \& Novak, M. D. (2021). Experimental research methodologies in organizational behavior management. Journal of
Organizational Behavior Management, 1-32. https://doi.org/10.1080/01608061.2020.1869137

21. Farrington, D. P., \& Ttofi, M. M. (2009). Schoolbased programs to reduce bullying and victimization. Campbell systematic reviews, 5(1), i-148. https://doi.org/10.4073/csr.2009.6

22. Fortuna, K. L., Naslund, J. A., LaCroix, J. M., Bianco, C. L., Brooks, J. M., Zisman-Ilani, Y., ... \& Deegan, P. (2020). Digital peer support mental health interventions for people with a lived experience of a serious mental illness: systematic review. JMIR mental health, 7(4), e16460. https://doi.org $10.2196 / 16460$

23. Gysbers, N. C., \& Henderson, P. (2014). Developing and managing your school guidance and counseling program. John Wiley \& Sons. (Hardcopy).

24. Kapp, A. (2020). The psychometric properties of the Academic Motivation Scale-College version of South African first-year university students (Doctoral dissertation, North-West University (South Africa). Available at: http://repository.nwu.ac.za/handle/10394/34857

25. Kennedy, T. D., Flach, Y., Detullio, D., Millen, D. H., Englebert, N., \& Edmonds, W. A. (2019). Exploring Emotional Intelligence and IQ as Predictors of Success of Foster Care Alumni. Journal of Child and Family Studies, 1-10. https://doi.org/10.1007/s10826019-01503-8

26. Kimmel, S. D., Gaeta, J. M., Hadland, S. E., Hallett, E., \& Marshall, B. D. (2021). Principles of harm reduction for young people who use drugs. Pediatrics, 147 (Supplement 2), S240-S248. https://doi.org/10.1542/peds.2020-023523G

27. Kiptala, W., \& Kipruto, J. (2021). Students' Perception of the Influence of Guidance and Counselling Services and Academic Performance in Baringo Country, Kenya. European Journal of Education and Pedagogy, 2(1), 32-35. https://doi.org/10.24018/ejedu.2021.2.1.12

28. Knight, M. A., Haboush-Deloye, A., Goldberg, P. M., \& Grob, K. (2019). Strategies and Tools to Embrace Prevention with Upstream Programs: A Novel Pilot Program for Enhancing Social and Emotional Protective Factors in Middle School Students. Children \& Schools, 41(4), 213-220. https://doi.org/10.1093/cs/cdz020

29. Köse, A. (2019). Program evaluation competencies for prospective school counseling practitioners. Uluslararası Eğitim Programları ve Öğretim 
Çalışmaları Dergisi, $\quad 9(1), \quad 33-52$. https://doi.org/10.31704/ijocis.2019.002

30. Kurunsaari, M., Tynjälä, P., \& Piirainen, A. (2021). Stories of professional development in physiotherapy education. Physiotherapy Theory and Practice, 1-14. https://doi.org/10.1080/09593985.2021.1888341

31. Low, P. K. F. (2018). Stakeholders' perceptions of school counselling in Singapore: a mixed method study (Doctoral dissertation, University of Southern Queensland).

Available at: http://eprints.usq.edu.au/id/eprint/35120

32. Lusky, M.B. \& Hayes, R.L. (2001) Collaborative Consultation and Programme Evaluation. Journal of Counselling and Development, 79 (1), 26-38. https://doi.org/10.1002/j.1556-6676.2001.tb01940.x

33. Maree, J. G., Fletcher, L., \& Pienaar, M. (2018). Enhancing the sense of self of peer supporters using life design-related counselling. South African Journal of Psychology, 48(4), 420-433. https://doi.org/10.1177/0081246317742246

34. Maturure, D. (2004). Problems faced by school counsellors in implementing guidance and counselling programmes in Masvingo district. Unpublished BSc Counselling Dissertation). Harare: Zimbabwe Open University. (Hardcopy)

35. Mbabazi, G. K., \& Bagaya, J. (2013). Guidancecounselling strategies and conformity with code of conduct in secondary schools in Gulu municipality, Uganda. International Journal of Education, 5(2), 3952. https://doi.org/10.5296/ije.v5i2.3211

36. Mekgwe, N. K., \& Kok, A. (2017). The personal career planning needs of secondary school learners in Botswana. International Journal of Educational Sciences, $\quad$ 17(1-3), 238-246. https://doi.org/10.1080/09751122.2017.1317156

37. Mintah, D. A. (2012). Assessment of the effectiveness of guidance and counselling services in second cycle schools in the Kwaebibrem District in the Eastern Region of Ghana (Doctoral dissertation, University of Cape Coast). Available at: http://hdl.handle.net/123456789/2751

38. Mitchell, K. R., Purcell, C., Forsyth, R., Barry, S., Hunter, R., Simpson, S. A., ... \& Moore, L. (2020). A peer-led intervention to promote sexual health in secondary schools: the STASH feasibility study. Public Health Research, 8(15), 1-152. https://doi.org/10.3310/phr08150

39. Moeti, B. (2016). Perceptions of teacher counsellors on assessment of guidance and counselling in Secondary Schools. International Journal of Learning,
Teaching and Educational Research, 15(6). Available at:

https://www.ijlter.org/index.php/ijlter/article/view/59 $\underline{3}$

40. Mtemeri, J. (2020). Peer pressure as a predictor of career decision-making among high school students in Midlands Province, Zimbabwe. Global Journal of Guidance and Counselling in Schools: Current Perspectives, $\quad 10(3), \quad 120-131$. https://doi.org/10.18844/gjgc.v10i3.4898

41. Mugai, W. J. J. (2020). Relationship Between Counsellors'powers and counselling outcomes of learners with behaviour problems in inclusive primary schools in Embu County, Kenya (Doctoral Dissertation, Chuka University). Available at: http://repository.chuka.ac.ke/handle/chuka/7895

42. Mughal, A. W. (2020). Secondary school students who drop out of school in rural Pakistan: The perspectives of fathers. Educational Research, 62(2), 199-215.

https://doi.org/10.1080/00131881.2020.1755604

43. Mwale, M., \& Muula, A. S. (2019). The efficacy of peer education in sexual behavioral change among school-going adolescents in Northern Malawi: A Quasi experiment. Journal of HIV/AIDS \& Social Services, $1-19$. https://doi.org/10.1080/15381501.2019.1620664

44. Mwoma, T., \& Pillay, J. (2015). Psychosocial support for orphans and vulnerable children in public primary schools: Challenges and intervention strategies. South African Journal of Education, 35(3). https://doi.org/10.15700/saje.v35n3a1092

45. Naidoo, P., \& Cartwright, D. (2020). Where to from here? Contemplating the impact of COVID-19 on South African students and student counselling services in higher education. Journal of College Student Psychotherapy, 1-15. https://doi.org/10.1080/87568225.2020.1842279

46. Nice, M. L., Joseph, M., Kolbert, J. B., Hilts, D. N., Crothers, L. M., \& Kratsa, K. (2021). Development of the School Counselor Efficacy for College Knowledge Questionnaire. Journal of Psychoeducational Assessment. https://doi.org/10.1177/07342829211021680

47. Ntinda, K., Maree, J. G., Mpofu, E., \& Seeco, E. (2014). In-school psychosocial support services for safeguarding children's rights: Results and implications of a Botswana study. School Psychology International, 35(3), 280-293. https://doi.org/10.1177/0143034313511005 
48. Ntuli, B., Mokgatle, M., \& Madiba, S. (2020). The psychosocial wellbeing of orphans: The case of early school leavers in socially depressed environment in Mpumalanga Province, South Africa. Plos one, 15(2). https://doi.org/10.1371/journal.pone.0229487

49. Ntwiga, S. M. (2015). Effectiveness of Guidance and Counseling program on students' Behaviour in public and private secondary schools in Meru south subcounty, Kenya. Unpublished M. Ed. Thesis, University of Nairobi. Available at: http://erepository.uonbi.ac.ke/handle/11295/90491

50. Nyumba, T., Wilson, K., Derrick, C. J., \& Mukherjee, N. (2018). The use of focus group discussion methodology: Insights from two decades of application in conservation. Methods in Ecology and evolution, 9(1), 20-32. https://doi.org/10.1111/2041210X.12860

51. Olweus, D., Solberg, M. E., \& Breivik, K. (2020). Long-term school-level effects of the Olweus Bullying Prevention Program (OBPP). Scandinavian journal of psychology, 61(1), 108-116. https://doi.org/10.1111/sjop.12486

52. Peek, L. (2008). Children and Disasters: Understanding Vulnerability, Developing Capacities, and Promoting Resilience an Introduction. Children, Youth and Environments, 18(1). Available at: https://www.jstor.org/stable/10.7721/chilyoutenvi.18 $\underline{1.0001}$

53. Pilarska, J. (2021). 6 The Constructivist Paradigm and Phenomenological Qualitative Research Design. In Research Paradigm Considerations for Emerging Scholars (pp. 64-83). Channel View Publications. https://doi.org/10.21832/9781845418281-008

54. Pincus, R., Hannor-Walker, T., Wright, L., \& Justice, J. (2020). COVID-19's effect on students: How school counselors rise to the rescue. NASSP Bulletin, 104(4),241-256. https://doi.org/10.1177/0192636520975866

55. Prior, J. (2016). The use of semi-structured interviews with young children. In Practical research with children (pp. 135-152). London: Routledge. Available at:

https://www.taylorfrancis.com/chapters/edit/10.4324/ 9781315676067-17/use-semi-structured-interviewsyoung-children-jess-prior

56. Riele, K. T. (2006). Youth 'at risk': further marginalizing the marginalized? Journal of education policy, 21(2), 129-145. https://doi.org/10.1080/02680930500499968
57. Rutondoki, E.N. (2000) Guidance and Counselling. Makerere University. Institute of Adult and Continuing Education. (Cited in Kiptala \& Kipruto, 2021).

58. Sahlberg, P. (2021). Finnish Lessons 3. 0: What Can the World Learn from Educational Change in Finland. Teachers College Press. Available at: https://books.google.co.za/books?hl=en \&lr=\&id=7A 4VEAAAQBAJ\&oi=fnd\&pg $=$ PP1\&dq=Sahlberg, + P $+(2021) .+$ Finnish + Lessons $+3 .+0:+$ What+Can+the + World+Learn + from + Educational $+\% 09$ Change + in $+\mathrm{F}$ inland. + Teachers + College + Press. \&ots $=K n 37 x b o K C$ $\underline{X}$ sig=51IPViVGB8ntt4NdnxKLe3movzU\&redir_e

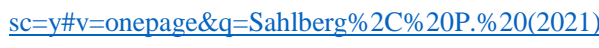
\%20Finnish\%20Lessons\%203.\%200\%3A\%20What \%20Can\%20the\%20World\%20Learn\%20from\%20E ducational\%20\%09Change\%20in\%20Finland.\%20T eachers $\% 20$ College $\% 20$ Press.\&f=false

59. Schmidt, L. K. (2016). Understanding hermeneutics. London: Routledge. Available at: https://philpapers.org/rec/SCHUH

60. Shariati, M., Babazadeh, R., Mousavi, S. A., \& Najmabadi, K. M. (2014). Iranian adolescent girls' barriers in accessing sexual and reproductive health information and services: a qualitative study. Journal of Family Planning and Reproductive Health Care, 40(4), 270-275. http://dx.doi.org/10.1136/jfprhc2013-100856

61. Shiferaw, K., Getahun, F., \& Asres, G. (2014). Assessment of adolescents' communication on sexual and reproductive health matters with parents and associated factors among secondary and preparatory schools' students in Debremarkos town, North West Ethiopia. Reproductive health, 11(1), 1-10. https://doi.org/10.1186/1742-4755-11-2

62. Sima, R. G. (2018). The challenges in the provision of counselling services in secondary schools in Tanzania. Papers in Education and Development, (29). Available at: https://journals.udsm.ac.tz/index.php/ped/article/vie $\underline{\mathrm{w} / 1451 / 1354}$

63. Swartz, S., Bhana, A., Moolman, B., Arogundade, E., Solomon, J., Timol, F., \& Vawda, M. (2014). " Opening locked doors": evaluating peer education in schools in the Western Cape province: a mixed methods longitudinal study. Available at: http://hdl.handle.net/20.500.11910/2783

64. Tewolde, A. I. (2021). Immigration and the (Ir) relevance of the South African Racial Classification System: Towards Transforming the Official Racial 
Categories. Society, 58(1), 54-59. https://doi.org/10.1007/s12115-021-00563-1

65. Tharp, R. G., Estrada, P., Dalton, S. S., \& Yamauchi, L. A. (2018). Teaching transformed: Achieving excellence, fairness, inclusion, and harmony. Routledge. https://doi.org/10.4324/9780429496943

66. Trevisan, M.S. \& Hubert, M. (2001) Implementing Comprehensive Guidance Programs Evaluation Support: Lessons Learned. In Professional School Counselling, 4 (3), 225-228. Available at: https://www.proquest.com/docview/213261289?pqorigsite $=$ gscholar $\&$ fromopenview $=$ true

67. Upadhyay, P. (2016). Sexual and reproductive health services: utilization pattern of adolescents in Nepal. The NEHU J, 14(2), 55-67.

68. Wade, C. \& Tarvis, C. (1993) Psychology. New York: Harpner Collins College Publishers. https://doi.org/10.1007/978-3-319-00161-6_3

69. Weare, K. (2015). What works in promoting social and emotional well-being and responding to mental health problems in schools. London: National Children's Bureau.

70. Wright-Berryman, J., Hudnall, G., Bledsoe, C., \& Lloyd, M. (2018). Suicide Concern Reporting among Utah Youths Served by a School-Based Peer-to-Peer Prevention Program. Children \& Schools, 41(1), 3544. https://doi.org/10.1080/02739615.2019.1630279

71. Yong, W. K., Husin, M. M., \& Kamarudin, S. (2021). Understanding Research Paradigms: A Scientific Guide. Journal of Contemporary Issues in Business and Government Vol, 27(2). https://doi.org/10.5430/ijhe.v6n5p26

73. York-Barr, J., Sommerness, J., Duke, K., \& Ghere, G. (2005). Special educators in inclusive education programmes: Reframing their work as teacher leadership. International Journal of Inclusive $\begin{array}{lll}\text { Education, } & 9 & \text { (2), }\end{array}$ https://doi.org/10.1177/0022466913501882

74. Zeiler, M., Kuso, S., Nitsch, M., Simek, M., Adamcik, T., Herrero, R. \& Waldherr, K. (2021). Online interventions to prevent mental health problems implemented in school settings: the perspectives from key stakeholders in Austria and Spain. European Journal of Public Health, 31 (Supplement_1), i71-i79. https://doi.org/10.1093/eurpub/ckab039 